\title{
Evaluating the impact of breed, pregnancy, and hair coat on body temperature and sweating rate of hair sheep ewes in the tropics 1
}

\author{
R. W. Godfrey, ${ }^{* 2}$ W. D. Preston, $*$ S. R. Joseph, ${ }^{*}$ L. LaPlace, $*$ P. E. Hillman, $\dagger$ \\ K. G. Gebremedhin, $\dagger$ C. N. Lee, + and R. J. Collier§ \\ *Agricultural Experiment Station, University of the Virgin Islands, St. Croix, USVI 00850; $\uparrow$ Department of Biological \\ and Environmental Engineering, Cornell University, Ithaca, NY 14853; \$Department of Human Nutrition, Food and \\ Animal Sciences, University of Hawaii-Manoa, Honolulu 96822; §William Parker Agricultural Research Center, \\ Department of Animal Science, University of Arizona, Tucson 85719
}

\begin{abstract}
The objective of this study was to evaluate the effect of pregnancy, breed, and hair coat on body temperature and sweating rate (SR) of hair sheep. St. Croix White (STX; $n=9)$ and Dorper $\times$ STX (DRPX; $n=9$ ) ewes (3.6 yr of age) were evaluated over $4 \mathrm{~d}$ at $126 \mathrm{~d}$ of gestation (PREG) and over $4 \mathrm{~d}$ at $46 \mathrm{~d}$ postpartum (OPEN) in the shade and sun and in the morning (AM; 0900 to $1200 \mathrm{~h}$ ) and afternoon (PM; 1300 to $1600 \mathrm{~h}$ ) after a $20 \mathrm{~min}$ acclimation to each condition on each day. Data loggers recorded vaginal temperature (VT) at 10-min intervals for 96 h. Rectal temperature (RT) was measured using a digital veterinary thermometer, and respiration rate (RR) was measured as breaths per minute (bpm). Sweating rate was calculated from measured air properties passing over a shaved $\left(300 \mathrm{~cm}^{2}\right)$ and unshaved area of the ewes' body using a portable calorimeter. Data were analyzed using GLM procedures of SAS (SAS Inst. Inc., Cary, NC) with breed, pregnancy status, sun exposure, and time of day as main effects. Mean temperature, relative humidity, temperaturehumidity index, wind speed, and solar radiation on the days of data collection were $28.2^{\circ} \mathrm{C}, 82.8 \%, 80.3$, $4.2 \mathrm{~km} / \mathrm{h}$, and $237.5 \mathrm{~W} / \mathrm{m}^{2}$, respectively. There was no difference $(P>0.10)$ in RT, RR, and SR between
\end{abstract}

DRPX and STX ewes. The PREG ewes had lower RT $(P<0.007)$ and SR $(P<0.0001)$ and higher RR $(P<0.007)$ than OPEN ewes $(38.5 \pm 0.2$ vs. $39.1 \pm$ $0.2^{\circ} \mathrm{C}, 70.2 \pm 3.1$ vs. $88.3 \pm 3.1 \mathrm{~g} \cdot \mathrm{m}^{-2} \cdot \mathrm{h}^{-1}$, and 79.5 \pm 2.2 vs. $72.1 \pm 2.2 \mathrm{bpm}$, respectively). During the PM, RR, RT $(P<0.05)$, and SR $(P<0.006)$ were higher than in the AM. In the sun, RR $(P<0.001)$ and SR $(P<0.0001)$ were higher than in the shade, but there was no difference $(P>0.10)$ in RT. There was no difference in SR $(P>0.10)$ between the shaved and unshaved area of the ewe. The DRPX ewes had higher $(P<0.0001)$ VT than STX ewes. The PREG ewes had higher $(P<0.001)$ VT than OPEN ewes during the night time and lower VT than the OPEN ewes during the day time $(P<0.0001)$. The OPEN ewes had a greater $(P<0.009)$ daily range of VT than PREG ewes did $\left(2.5 \pm 0.4\right.$ vs. $1.1 \pm 0.4^{\circ} \mathrm{C}$, respectively), but there was no breed difference $(P>0.10)$. Hair coat did not have an influence on the SR of the ewes, and PREG ewes appeared to use increased respiration as opposed to sweating to help control RT. The narrower range of body temperature, measured as VT, of PREG compared to OPEN ewes may be a protective mechanism for the developing fetus.

Key words: body temperature, hair sheep, heat stress, pregnancy, sweating rate, tropics

\footnotetext{
${ }^{1}$ This project was supported by USDA-NIFA Special Research Projects TSTAR grant award number 2008-34135-19505. Undergraduate students Serena Joseph and Lucas LaPlace were supported by USDA-NIFA Resident Instruction in the Insular Areas Program award number 2012-38416-19977. This project was a contribution to the USDA-NIFA Multistate Project W-2173
}

(Impacts of Stress Factors on Performance, Health, and WellBeing of Farm Animals).

${ }^{2}$ Corresponding author: rgodfre@uvi.edu

Received October 14, 2016.

Accepted May 5, 2017. 


\section{INTRODUCTION}

Heat stress is a common problem in ruminant livestock production throughout the tropics and other areas with high temperatures and/or humidity. Body temperature and respiration rate ( $\mathbf{R R})$ are commonly used indicators of hyperthermia in animals. Respiration rate increases during periods of heat stress to utilize evaporative cooling from the membranes of the oral and nasal cavities to regulate body temperature, and the increased air movement through the respiratory system dissipates heat (Hales and Brown, 1974; Hofman and Riegle, 1977). Heat stress of ewes during pregnancy has been reported to result in smaller lambs and a decreased placental weight (Dreiling et al., 1991; McCrabb et al., 1993). In a review by Marai et al. (2007), the authors cited studies that reported sweating in wool sheep is not very effective at regulating body temperature due to the wool cover. Because sheep in the tropics tend to have short hair coats, as opposed to heavy wool fleeces, sweating may play a more significant role in the ability of hair sheep to maintain body temperature within a thermoneutral state. St. Croix White (STX) hair sheep are well adapted to the hot, humid climate found in the U.S. Virgin Islands, but other breeds of sheep such as the Dorper, which was initially selected for arid areas (Baker et al., 1999), may not be as suited to the humid tropics. In support of this, it has been reported that STX ewes have lower body temperatures than Dorper $\times$ STX (DRPX) ewes under tropical conditions (Godfrey et al., 2013). Assessing the sweating rate (SR) of tropically adapted breeds of hair sheep can lead to the development of more efficient strategies to employ in tropical environments to evaluate and alleviate heat stress. The objective of this study was to evaluate the impact of pregnancy, breed, and hair coat on the body temperature and SR of STX and DRPX hair sheep ewes in a tropical environment.

\section{MATERIALS AND METHODS}

Animals were managed in accordance with the Guide for the Care and Use of Agricultural Animals in Agricultural Research and Teaching (FASS, 1999), and experimental procedures were approved by the University of the Virgin Islands Animal Care and Use Committee. Ewes grazed guinea grass (Panicum maximum) pastures in a rotational grazing system throughout gestation and the postpartum period.

St. Croix White $(n=9)$ and DRPX $(n=9)$ ewes (3.6 yr of age) were evaluated at $126 \mathrm{~d}$ of gestation (PREG; June) and again at $46 \mathrm{~d}$ postpartum (OPEN; August). Ewes were evaluated over $4 \mathrm{~d}$, during ges- tation and the postpartum period, in the shade or sun and in the morning (AM; 0900 to $1200 \mathrm{~h}$ ) or afternoon (PM; 1300 to 1600 h). Within each 4 -d period, all ewes were evaluated in the sun and shade and in the AM and PM. On the days when evaluations were being conducted, ewes and lambs were brought in from pasture, separated from the ewes in the morning, and placed in a pen with access to shade and water. At the end of each day, ewes and lambs were placed back into a guinea grass (Panicum maximum) pasture until the following morning. On the first day of each 4-d evaluation period, temperature data loggers (StowAway TidbiT; Onset Computer Corp., Bourne, MA) were placed in the vagina of each ewe to record vaginal temperature $(\mathbf{V T})$ at 10-min intervals for $96 \mathrm{~h}$. Previous work has shown that VT is highly correlated with rectal temperature (RT) in hair sheep ewes (George et al., 2014).

On each day of evaluation, ewes were allowed to acclimate in the shade or sun for 20 min prior to collecting any measurements in the AM and PM. Ewes were placed on a shearing stand to immobilize them for RT, RR, and SR measurements in the sun or shade. Rectal temperature was measured using a digital veterinary thermometer (GLA M700; GLA Agricultural Electronics, San Luis Obispo, CA; accuracy, $\pm 0.1^{\circ} \mathrm{C}$ ), and RR was measured by holding a hand in front of the muzzle and counting breaths for $15 \mathrm{~s}$ and adjusting to breaths per minute (bpm).

On the first day of evaluation, each ewe had an area $\left(300 \mathrm{~cm}^{2}\right)$ shaved over the left flank using an electric clipper and a \#40 blade. Sweating rate was measured over the shaved area and a corresponding unshaved area on the right flank using a bovine evaporation meter (BEM; Gebremedhin et al., 2008) that measured air properties passing over the areas of the ewes' body. The equipment consists of a portable calorimeter that has been modified to directly and accurately measure evaporation (sweating) rate from the sample area. The BEM allows measurement of SR $\left(\mathrm{g} \cdot \mathrm{m}^{-2} \cdot \mathrm{h}^{-1}\right)$ from a 76 - by $102-\mathrm{mm}$ area of body surface. Air velocity over the sample area was set at $1.0 \mathrm{~m} / \mathrm{s}$. A transparent film above the sample area allows unimpeded exposure to solar radiation.

Ambient conditions during each data collection period were monitored using a weather station located at the UVI Sheep Research Facility (Vantage Pro2; Davis Instruments Corp., Hayward, CA). The station measured temperature, relative humidity, wind speed, and solar radiation (average and maximum). Temperature-humidity index (THI) was calculated using the formula $\mathrm{THI}=(0.8 \times \mathrm{T})+[(\mathrm{RH} / 100) \times(\mathrm{T}-14.4)]$ +46.4 , where $\mathrm{T}$ is the temperature $\left({ }^{\circ} \mathrm{C}\right)$ and $\mathrm{RH}$ is the relative humidity (NOAA, 1976). The environmental conditions during each period and time of day within each period are shown in Table 1. 
Table 1. Environmental conditions during data collection

\begin{tabular}{lcccc}
\hline \hline & Mean $^{1}$ & Range $^{1}$ & AM $^{2}$ & PM $^{2}$ \\
\hline Pregnant ewes (June) & & & & \\
Temperature, ${ }^{\circ} \mathrm{C}$ & 27.9 & $25-31$ & 29.5 & 29.7 \\
Relative humidity, \% & 83.5 & $67-93$ & 78.2 & 77.1 \\
Temperature-humidity index & 79.9 & $76-84$ & 81.8 & 81.9 \\
Wind speed, km/h & 4.4 & $0-11$ & 6.5 & 6.3 \\
Average solar radiation, W/m ${ }^{2}$ & 198.1 & $0-1,080$ & 496.7 & 456.6 \\
Maximum solar radiation, W/m ${ }^{2}$ & 237.6 & $0-1,136$ & 607.8 & 535.1 \\
Open ewes (August) & & & & \\
Temperature, ${ }^{\circ} \mathrm{C}$ & 28.5 & $25-32$ & 30.6 & 31.5 \\
Relative humidity, \% & 82.1 & $67-95$ & 75.5 & 72.5 \\
Temperature-humidity Index & 80.6 & $76-85$ & 83.1 & 83.9 \\
Wind speed, km/h & 3.9 & $0-13$ & 6.7 & 8.7 \\
Average solar radiation, W/m ${ }^{2}$ & 273.9 & $0-1,104$ & 671.8 & 826.6 \\
Maximum solar radiation, W/m & 315.6 & $0-1,176$ & 800.6 & 908.7 \\
\hline
\end{tabular}

${ }^{1}$ Mean and range of values for the entire 4-d measurement period within each time period (pregnant and nonpregnant).

${ }^{2}$ Mean values on each day of measurement between 0900 and $1200 \mathrm{~h}$ (AM) and 1210 to $1600 \mathrm{~h}(\mathrm{PM})$.

Rectal temperature, RR, and SR were analyzed using GLM procedures of SAS (SAS Inst. Inc., Cary, NC) with breed (STX and DRPX), pregnancy status (PREG and OPEN), time of day (AM and PM), location (sun and shade), and hair coat (shaved and unshaved for SR only) as main effects. Mean separation was conducted using the PDIFF option. There were no significant interactions among breed, pregnancy status, time of day, location, and hair coat for RR, RT, and SR, so only means for main effects are reported. Serial VT samples were analyzed using repeated measures in GLM with breed, pregnancy status, time of day, and the appropriate interactions in the model. The magnitude of change in VT during a day ( $0000 \mathrm{~h}$ to $2400 \mathrm{~h})$ was calculated as the difference between the highest and the lowest VT within each day. Breed, day, and pregnancy status were used in the model to analyze magnitude of change in VT over the 4-d sampling period. All results are presented as least squares means \pm SEM.

\section{RESULTS}

There was no difference $(P>0.10)$ in RT, RR, or SR between STX and DRPX ewes (Table 2). Pregnant ewes had lower RT $(P<0.0007)$, higher RR $(P<0.0007)$, and lower SR $(P<0.0001)$ than OPEN ewes. In the AM, RT, RR $(P<0.05)$, and SR $(P<0.006)$ were lower than in the PM. There was no difference $(P>0.10)$ in RT between ewes evaluated in the sun or shade, but RR and SR were higher in the sun than in the shade $(P<$ $0.0001)$. There was no difference $(P>0.10)$ in SR measured over the shaved or unshaved areas on the ewes $\left(80.1 \pm 3.1\right.$ vs. $78.4 \pm 3.1 \mathrm{~g} \cdot \mathrm{m}^{-2} \cdot \mathrm{h}^{-1}$, respectively).
Table 2. Rectal temperature, respiration rate, and sweating rate of St. Croix White and Dorper $\times$ St. Croix White ewes by breed, pregnancy status, time of day, and location ${ }^{1}$

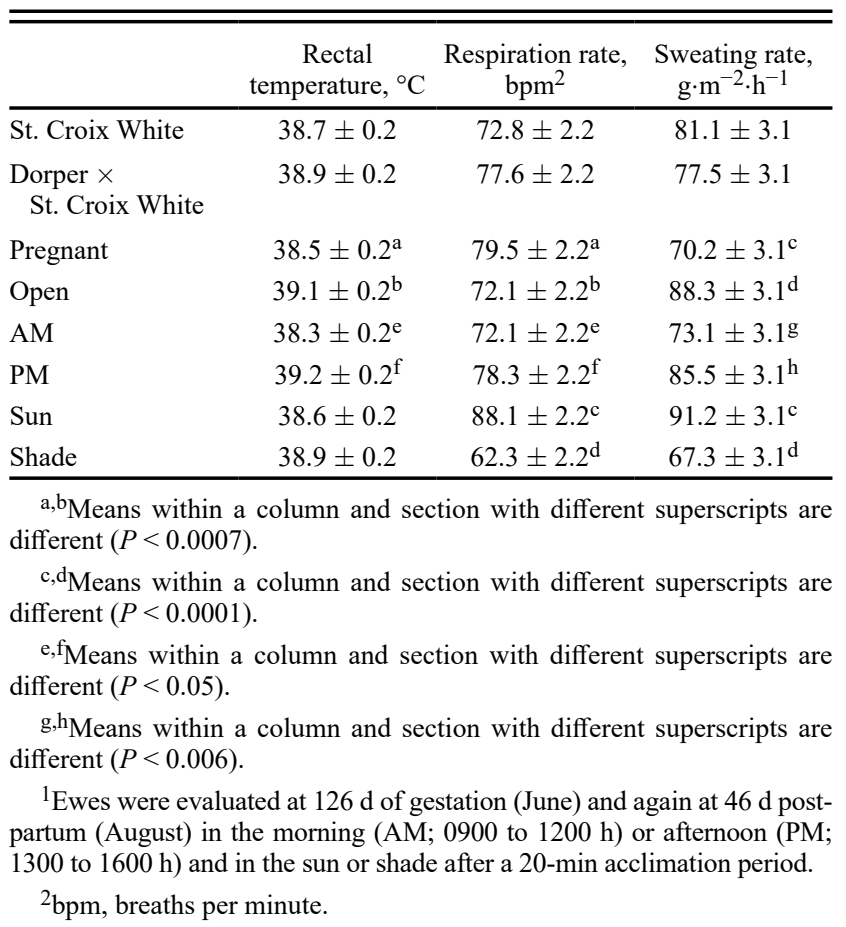

Vaginal temperature was higher $(P<0.0001)$ in DRPX ewes compared to STX ewes (Fig. 1). Pregnant ewes had higher $(P<0.0001) \mathrm{VT}$ than OPEN ewes from midnight to $1030 \mathrm{~h}$ (Fig. 2). Between $1030 \mathrm{~h}$ and $1820 \mathrm{~h}$, VT was lower in PREG ewes $(P<0.0001)$, except for a temporary dip in VT of OPEN ewes between 1220 and $1250 \mathrm{~h}$. From 1820 to $2400 \mathrm{~h}$, there was no difference $(P$ $>0.10$ ) in VT between PREG and OPEN ewes (Fig. 2).

Open STX ewes had the lowest VT from midnight to $1010 \mathrm{~h}$ and OPEN DRPX ewes had the highest VT from $1210 \mathrm{~h}$ to $1820 \mathrm{~h}(P<0.001$; Fig. 3). Open ewes had a greater $(P<0.009)$ magnitude of change in VT during the day than PREG ewes $(2.5 \pm 0.4$ vs. $1.1 \pm$ $0.4^{\circ} \mathrm{C}$, respectively), but there was no difference $(P>$ $0.10)$ between STX and DRPX ewes $(2.2 \pm 0.4$ vs. 1.5 $\pm 0.4^{\circ} \mathrm{C}$, respectively) and OPEN STX ewes had the largest $(P<0.007)$ magnitude of change (Fig. 4$)$.

\section{DISCUSSION}

The higher body temperature of DRPX ewes compared to STX ewes, measured as VT in this study, is in agreement with previous work in our lab where we reported that DRPX ewes had higher VT than STX ewes (Godfrey et al., 2013). Because the Dorper breed was developed in a hot, arid climate (Baker et al., 1999), it may not have the tolerance for the hot, humid climate of the Caribbean that the STX breed does even when 


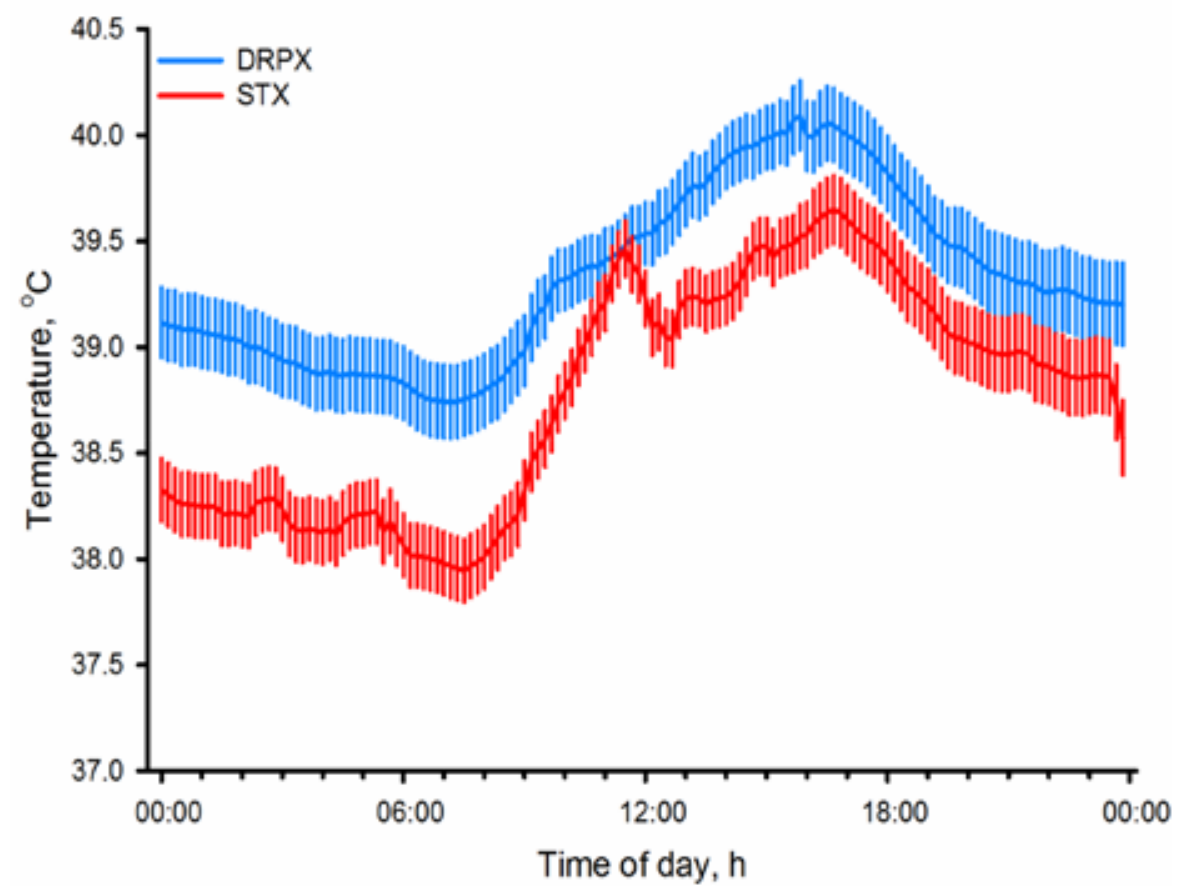

Figure 1. Daily profile (least squares means \pm SEM) of vaginal temperature of St. Croix White (STX; red line) and Dorper $\times$ St. Croix White (DRPX; blue line) ewes averaged over a 96-h period. The vaginal temperature of DRPX ewes was higher than that of STX ewes $(P<0.0001)$.

crossed with the STX. The lack of difference in RT, RR, and SR between breeds is likely due to the fact that these traits were all measured as single observations each day while the VT was measured serially at 10-min intervals over $96 \mathrm{~h}$. We have observed similar relationships among single vs. serial observations collected in a previous study where some of the body temperature measurements were collected using single observation thermal images or RT, and VT was measured serially using data loggers (George et al., 2014).

The PREG ewes had higher RR than the OPEN ewes, and this may have contributed to their ability to maintain a lower RT even with a lower SR compared to OPEN ewes. This was not apparent when compar-

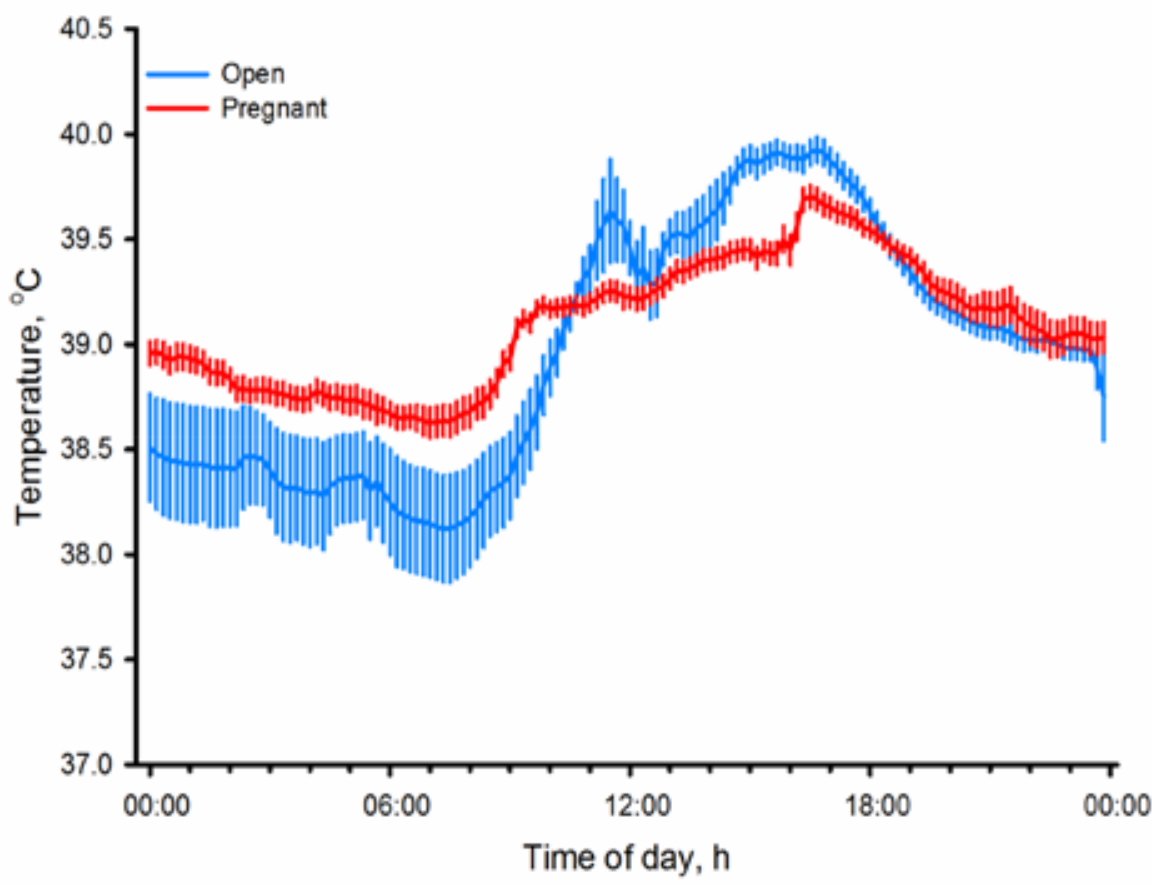

Figure 2. Daily profile (least squares means \pm SEM) of vaginal temperature of pregnant (red line) and open (blue line) ewes averaged over a 96-h period. The time of day $\times$ pregnancy status interaction was significant $(P<0.0001)$. 


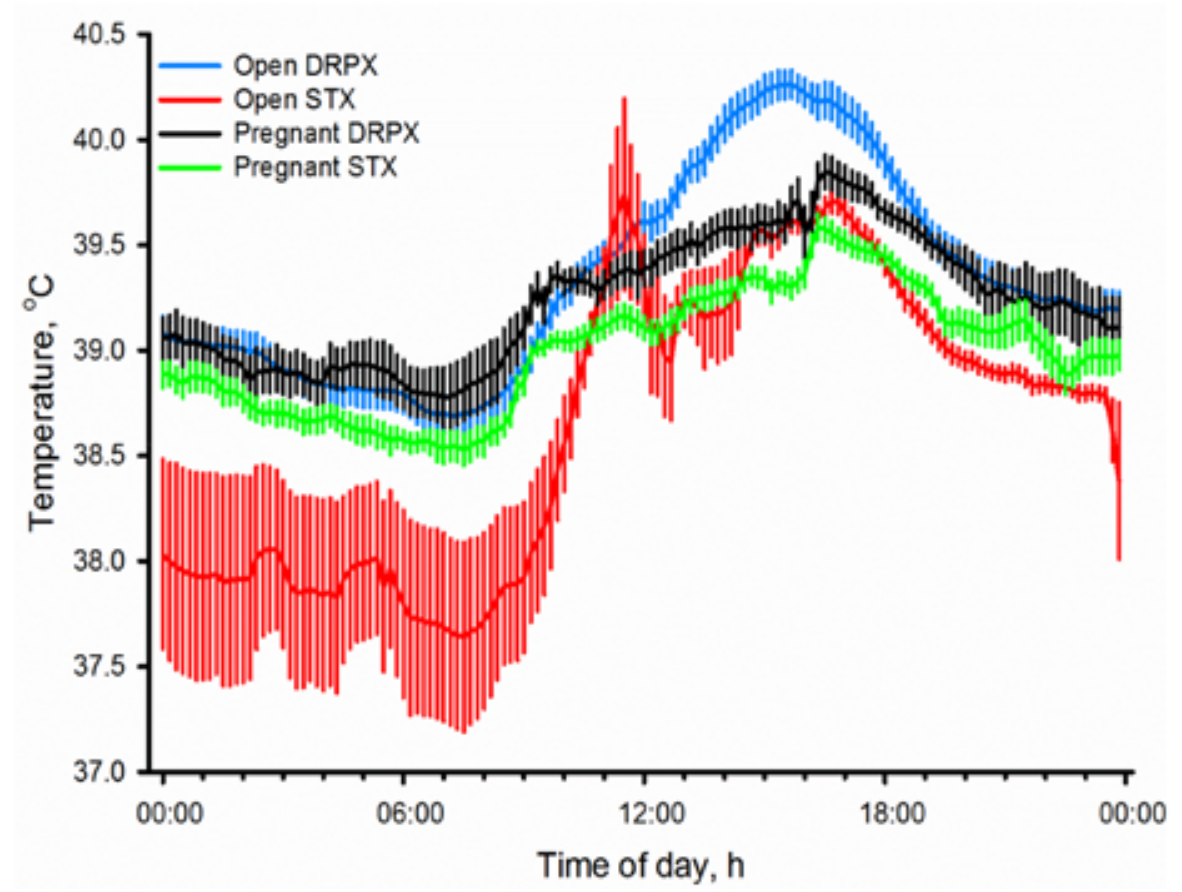

Figure 3. Daily profile (least squares means $\pm \mathrm{SEM}$ ) of vaginal temperature of pregnant and open St. Croix White (STX; green and red lines, respectively) and Dorper $\times$ St. Croix White (DRPX; black and blue lines, respectively) ewes pooled over a 96-h period. Breed and pregnancy status were significant $(P<0.001)$.

ing ewes evaluated in the morning and afternoon. The ewes evaluated in the afternoon had greater RR, RT, and SR, indicating that they were not able to use respiration or sweating to regulate body temperature. Both sheep and cattle have been shown to increase RR in response to elevated ambient temperatures as a method to keep core body temperature from rising (Hales and Brown, 1974; Llamas-Lamas and Combs, 1990; Mader et al., 2002). When sheep were housed at either
24 or $36^{\circ} \mathrm{C}$, there was an increase in RT of $0.8^{\circ} \mathrm{C}$ with a concomitant increase in RR from 76.2 to $156 \mathrm{bpm}$ as well (Llamas-Lamas and Combs, 1990).

The environmental conditions at each time of day may have played a role in the changes in RT and RR even though temperature was less than $1{ }^{\circ} \mathrm{C}$ and THI was less than 1 unit higher in the PM than in the AM across both time periods (Table 1). During the evaluation of the PREG ewes, the average and maximum so-

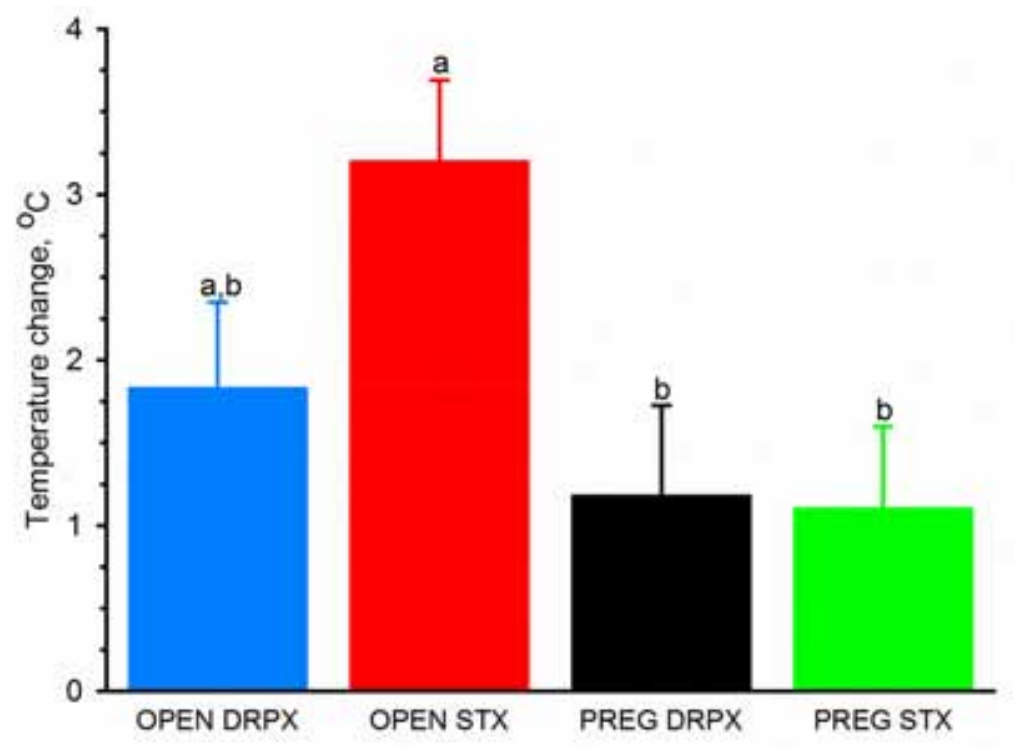

Figure 4. Magnitude of change (least squares means \pm SEM) of vaginal temperature of pregnant (PREG) and nonpregnant (OPEN) St. Croix White $(\mathrm{STX})$ and Dorper $\times$ St. Croix White (DRPX) ewes. ${ }^{\mathrm{a}, \mathrm{b}}$ Bars with different superscripts are different $(P<0.007)$. 
lar radiation levels were similar between the AM and PM time periods, but during the open evaluation, both average and maximum solar radiation increased in the afternoon (Table 1). The higher solar radiation during the PM period, at least for the OPEN ewes, may have played a role in causing the higher RT, RR, and SR measured at this time. The elevated RT during the afternoon does agree with the VT profiles shown in Fig. 1 and 2 and our previous work (Godfrey et al., 2013), where VT begins increasing by $0900 \mathrm{~h}$ each day regardless of breed or pregnancy status.

In the comparison of PREG to OPEN ewes, RT and SR were lower and RR was higher in PREG ewes further supporting the significance of $R R$ in regulating the body temperature of hair sheep. Collier et al. (2009) reported that evaporative heat loss is the primary route of heat dissipation for cattle exposed to thermal environments above their thermal neutral zone. Cattle are panting animals and lose some latent heat by this route, but skin surface evaporation of sweat is the primary means of latent heat loss during heat stress (Collier and Beede, 1985). This may be different in sheep, especially in wool breeds, where the fleece provides a significant boundary layer between the skin and the ambient air (Marai et al., 2007). Hofman and Riegle (1977) reported that respiratory evaporative cooling can account for $59 \%$ of total heat loss in shorn sheep and $65 \%$ in unshorn sheep. It has been reported that removing the fleece from wool sheep can reduce RR and delay the onset of panting (Bligh, 1963; Phillips and Raghavan, 1970).

The hair coat of animals plays a critical role in heat and moisture transfer from the skin surface (Gebremedhin et al., 1984; Jiang et al., 2005). The hair coat, which traps air to provide insulation in cold weather becomes an obstruction for evaporative cooling by reducing the velocity and moisture gradient through the fur layer in hot and humid conditions. The hair sheep breed used in the present study did not have any difference in SR between the shaved and unshaved areas, indicating that the short hair coat found on these animals $\left(2 \mathrm{~cm}\right.$ in length and 200 hairs $/ \mathrm{cm}^{2}$; Creighton et al., 2011) may not play a significant role in limiting or enhancing evaporative heat loss and contributes to their tropical adaptation.

In support of the need for thermal control during pregnancy, studies in dairy cattle have shown that heat stress can reduce fertility and embryonic survival (Dunlap and Vincent, 1971; Putney et al., 1988; Ealy et al., 1993). In cattle, the deleterious effects of maternal heat stress decline as pregnancy proceeds (Ealy et al., 1993), which may reflect acquisition of thermal resistance by the embryo as it progresses to the blastocyst stage (Edwards and Hansen, 1997). In sheep, heat-stressed ewes produced lambs that were smaller than lambs of control ewes (Dreiling et al., 1991; McCrabb et al., 1993). The smaller lambs can be attributed to several contributing factors that occur in heatstressed ewes. Uterine blood flow decreased by 20 to $30 \%$ in heat-stressed ewes with a $1{ }^{\circ} \mathrm{C}$ increase in core body temperature (Dreiling et al., 1991), and placenta weight was decreased in heat-stressed ewes at 80 and $140 \mathrm{~d}$ of gestation (McCrabb et al., 1993).

In the current study, the lower RT and diurnal change in VT, and higher RR, of the PREG ewes may be part of a physiological response to help protect the developing fetus from exposure to elevated temperatures in utero during the final trimester of pregnancy, even though the fetus is fairly well developed at this point. The lower magnitude of change in VT in PREG ewes is in contrast to some preliminary results from our laboratory (Godfrey et al., 2012) showing that there was no difference in magnitude of change in VT between PREG and OPEN Senepol cattle $(1.20 \pm 0.08$ vs. $1.22 \pm 0.08^{\circ} \mathrm{C}$, respectively).

The spike in VT of OPEN STX ewes at $1100 \mathrm{~h}$ (Fig. 3) is not observed in any of the other groups, but it is detectable in the STX ewes (Fig. 1) and the OPEN ewes (Fig. 2). The smaller magnitude spikes seen in the 2 latter groups are probably due to some dilution because they also contain PREG and DRPX ewes in the groups, respectively. The rate of increase in VT of OPEN ewes appears to be greater, especially between 0700 and $1100 \mathrm{~h}$, and indicates that they are accumulating heat more rapidly than PREG ewes as the day warms up. The time when this rapid increase in VT is occurring coincides with the time of day when both ambient temperature and THI are increasing rapidly (Godfrey et al., 2013). This difference in the rate of increase is also evident in the STX compared to the DRPX ewes (Fig. 1) and in the comparison of the PREG and OPEN ewes between breeds (Fig. 3). In fact, the OPEN STX ewes had the steepest increase in VT compared to the PREG STX and OPEN and PREG DRPX ewes. It is unknown if this rapid increase in VT between 0700 and $1200 \mathrm{~h}$ is due to a physiological trait of the STX ewes that is part of their tropical adaptation or the fact that their VT was the lowest during the time between midnight and $0700 \mathrm{~h}$ and it is compensatory in nature. It also appears that the OPEN STX ewes reached their maximum VT approximately 4 to $5 \mathrm{~h}$ earlier than the OPEN DRPX ewes even though they had lower VT during the preceding early morning hours. In a previous study, we demonstrated that VT of lactating STX and DRPX ewes displayed similar diurnal profiles with the DRPX having a higher VT, but there was no apparent difference in the rate of change 
during the morning hours as the ambient temperature increased (Godfrey et al., 2013).

The presence or absence of hair did not alter evaporative heat loss from the skin surface, i.e., sweating, and sweating does not appear to play a major role in regulating body temperature in hair sheep ewes. It does appear that RR may play a more significant role in regulating body temperature, especially in PREG ewes that had an increased RR but narrower range of body temperature, measured as VT, compared to OPEN ewes. This may be a protective mechanism for the developing fetus even at the late stage of gestation evaluated in this study. Further work needs to be done to evaluate ewe body temperature at earlier stages of gestation.

\section{LITERATURE CITED}

Baker, R. L., D. M. Mwamachim, J. O. Audho, E. O. Aduda, and W. Thorpe. 1999. Genetic resistance to gastro-intestinal nematode parasites in Red Maasai, Dorper and Red Maasai $\times$ Dorper ewes in the sub-humid tropics. Anim. Sci. 69:335-344. doi:10.1017/S1357729800050906

Bligh, J. 1963. Inhibition of thermal polypnoea in the closely shorn sheep. J. Physiol. 168:764-781. doi:10.1113/jphysiol.1963. sp007221

Collier, R. J., and D. K. Beede. 1985. Thermal stress as a factor associated with nutrient requirements and interrelationships. In: L. McDowell, editor, Nutrition of grazing ruminants. Academic Press, New York, NY. p. 59-71. doi:10.1016/B978-0-12483370-8.50011-2

Collier, R. J., T. R. Bilby, M. E. Rhoads, L. H. Baumgard, and R. P. Rhoads. 2009. Effects of climate change on dairy cattle production. Ann. Arid Zone 47:1-12.

Creighton, T., A. M. Hogg, and R. W. Godfrey. 2011. Evaluating the influence of breed on hair coat characteristics and body temperature of hair sheep in the tropics. J. Anim. Sci. 89(Suppl. 2):33.

Dreiling, C. E., F. S. Carman, III, and D. E. Brown. 1991. Maternal endocrine and fetal metabolic responses to heat stress. J. Dairy Sci. 74:312-327. doi:10.3168/jds.S0022-0302(91)78175-7

Dunlap, S. K., and C. K. Vincent. 1971. Influence of postbreeding thermal stress on conception rate in beef cattle. J. Anim. Sci. 32:1216-1218. doi:10.2527/jas1971.3261216x

Ealy, A. D., M. Drost, and P. J. Hansen. 1993. Developmental changes in embryonic resistance to adverse effects of maternal heat stress in cows. J. Dairy Sci. 76:2899-2905. doi:10.3168/ jds.S0022-0302(93)77629-8

Edwards, J. L., and P. J. Hansen. 1997. Differential responses of bovine oocytes and preimplantation embryos to heat shock. Mol. Reprod. Dev. 46:138-145. doi:10.1002/(SICI)10982795(199702)46:2<138::AID-MRD4>3.0.CO;2-R

FASS. 1999. Guide for the care and use of agricultural animals in agricultural research and teaching. 1st rev. ed. Federation of Animal Science Societies, Savoy, IL.
Gebremedhin, K. G., P. E. Hillman, C. N. Lee, R. J. Collier, S. T. Willard, J. Arthington, and T. M. Brown-Brandl. 2008. Sweating rates of dairy cows and beef heifers in hot conditions. Trans. ASABE 51:2167-2178. doi:10.13031/2013.25397

Gebremedhin, K. G., W. P. Porter, and R. G. Warner. 1984. Heat flow through pelage of calves-A sensitivity analysis. Trans. ASAE 27:1140-1143. doi:10.13031/2013.32935

George, W. D., R. W. Godfrey, R. C. Ketring, M. C. Vinson, and S. T. Willard. 2014. Relationship among eye and muzzle temperatures measured using digital infrared thermal imaging and vaginal and rectal temperatures in hair sheep and cattle. J. Anim. Sci. 92:4949-4955. doi:10.2527/jas.2014-8087

Godfrey, R. W., M. C. Vinson, and R. C. Ketring. 2013. The effect of a split feeding regimen and breed on body temperature of hair sheep ewes in the tropics. J. Anim. Sci. 91:5202-5207. doi:10.2527/jas.2013-6559

Godfrey, R. W., A. J. Weis, P. E. Hillman, K. G. Gebremedhin, C. N. Lee, and R. J. Collier. 2012. Evaluation of body temperature and sweating rate of Senepol cows in the tropics. J. Anim. Sci. 90(Suppl. 3):241. (Abstr.)

Hales, J. R. S., and G. D. Brown. 1974. Net energetic and thermoregulatory efficiency during panting in the sheep. Comp. Biochem. Physiol. A 49:413-422. doi:10.1016/0300-9629(74)90557-X

Hofman, W. F., and G. D. Riegle. 1977. Thermorespiratory responses of shorn and unshorn sheep to mild heat stress. Respir. Physiol. 30:327-338. doi:10.1016/0034-5687(77)90039-1

Jiang, M., K. G. Gebremedhin, and L. D. Albright. 2005. Numerical simulation of coupled heat and mass transfer through the hair coat. ASAE Annual International Meeting. St. Joseph, MI. Paper No. 044038.

Llamas-Lamas, G., and D. K. Combs. 1990. Effects of environmental temperature and ammoniation on utilization of straw by sheep. J. Anim. Sci. 68:1719-1725. doi:10.2527/1990.6861719x

Mader, T. L., S. M. Holt, G. L. Han, M. S. Davis, and D. E. Spiers. 2002. Feeding strategies for managing heat load in feedlot cattle. J. Anim. Sci. 80:2373-2382. doi:10.2527/2002.8092373x

Marai, I. F. M., A. A. El-Darawany, A. Fadiel, and M. A. M. AbdelHafez. 2007. Physiological traits as affected by heat stress in sheep-A review. Small Rumin. Res. 71:1-12. doi:10.1016/j. smallrumres.2006.10.003

McCrabb, G. J., B. J. McDonald, and L. M. Hennoste. 1993. Heat stress during mid-pregnancy in sheep and the consequences for placental and fetal growth. J. Agric. Sci. 120:265-271. doi:10.1017/S0021859600074311

NOAA. 1976. Livestock hot weather stress. Operations Manual Letter C-31-76. National Oceanic and Atmospheric Administration, Kansas City, MO.

Phillips, G. D., and G. V. Raghavan. 1970. Responses of unshorn and shorn sheep to thermal stress. J. Physiol. 208:317-328. doi:10.1113/jphysiol.1970.sp009122

Putney, D. J., M. Drost, and W. W. Thatcher. 1988. Embryonic development in superovulated dairy cattle exposed to elevated ambient temperature between days 1 to 7 post insemination. Theriogenology 30:195-209. doi:10.1016/0093-691X(88)90169-0 